\title{
Symmetry Formation by Undergraduates in Successive Matching: A Re-evaluation of Urcuioli's Theory
}

\author{
Masaki Ishizuka, Tetsumi Moriyama \\ Tokiwa University, Mito, Japan
}

\begin{abstract}
The present study investigates whether undergraduates can demonstrate symmetry in a successive matching procedure similar to Urcuioli's procedure (2008). It also examines the relationships between their symmetry formation and their verbal behavior in the matching tasks. Two experiments were conducted. In the first experiment, four students received concurrent baseline training on symbolic (hue-form), hue-identity, and form-identity successive matching. A fixed ratio schedule was used during the sample presentation and a variable interval was used during the comparison presentation. Only one participant who showed clear differentiation of responding demonstrated such symmetry in the test phase as defined by Urcuioli (2008). The relationships between the participants' responding and their verbal behavior were not clear. In the second experiment, five students received training similar to that in the first experiment. However, the schedules of reinforcement (fixed ratio for the sample and fixed interval for the comparison) were changed so that differentiation of responding developed sufficiently during the baseline phase. In the second experiment, four participants demonstrated symmetry. Although there were some relationships between their symmetry formation and their verbal behavior in the tasks, both behavioral processes were thought to be products of the contingencies of reinforcement in the successive matching, as they were derived from the procedural change. We discussed our findings from the viewpoints of Urcuioli's and Sidman's theories (2000).
\end{abstract}

Keywords: symmetry, successive matching procedure, Urcuioli's theory, Sidman's theory, undergraduates

When we hear the vocal sound, "Apple!" we may think of an apple even if we do not see an actual apple at that time. Furthermore, when we are asked to choose an apple from among various fruits, we are able to do so. Thinking of an apple or the choice of an apple like that is symbolic behavior. The way we acquire symbolic behavior involves training in stimulus equivalence. In the above example, there is an equivalent relation between the stimuli of vocal sounds, the image, and the actual apple. In training in stimulus equivalence, the presentation of one class of stimuli (e.g., the vocal sound "apple") sets the occasion for responses made to other stimulus classes (e.g., an image of an apple or the actual apple). When a child learns a large number of words, the child needs training in stimulus equivalence. For example, when we teach a child to read, a spoken word (the name "apple") is connected to a visual stimulus (a picture of an apple or an actual apple) and then to written symbols (the written word "apple"). Eventually, the child knows that the written word "apple" means an apple as an actual object. Although such equivalent relations between stimuli are learned through training,

\footnotetext{
* Acknowledgments: We would like to thank Editage (www.editage.jp) for English language editing. Masaki Ishizuka, Master of Human Science, Graduate School of Human Science, Tokiwa University, Mito, Japan. Tetsumi Moriyama, Ph.D., Emeritus Professor, Department of Psychology, Tokiwa University, Mito, Japan.
} 
behavior analysis demonstrates that the relations emerge even without direct training (Sidman, 1971; Sidman \& Cresson, 1973). The most important equivalent relation for stimulus equivalence is symmetry, which is the topic of the present study. Symmetry is an emergent relation derived from conditional discrimination training such as matching-to-sample training.

An emergent relation is a new behavioral relation emerging as a byproduct of other relations, rather than through differential reinforcement (Catania, 2013). An equivalence class is a stimulus class that includes all possible emergent relations among its members. The properties of an equivalence class are derived from the logical relations of reflexivity, symmetry, and transitivity (Sidman \& Tailby, 1982). Based on the notation of the relations between stimuli by Sidman and Tailby (1982), $a R b$ is the procedurally defined conditional relation between stimuli, $a$ and $b$. The first letter of each R represents a sample and the second the matching comparison. Reflexivity refers to an emergent relation $a R a$ and $b R b$, in which identity matching occurs in matching-to-sample when the following holds true: "if $a$, then $a$," and "if $b$, then $b$ ". Symmetry refers to an emergent relation that holds bidirectionally between two different stimuli in which, if $a R b$, then $b R a$. Thus, symmetry requires the sample and comparison to be interchangeable in matching-to-sample. Transitivity refers to the transfer of the relation to new combinations through shared membership, in which if $a R b$ and $b R c$, then $a R c$. The equivalence class requires the emergence of all three stimulus relations after only some are trained through conditional discrimination in matching-to-sample contingencies. Stimuli that are members of an equivalence class are likely to be functionally equivalent (Sidman et al., 1982).

In early experiments, Sidman (1971) and Sidman and Cresson (1973) found that youth with delayed intellectual development exhibited similar responses to such equivalence classes, consisting of pictures, their printed names, and their dictated names. From the findings, Sidman et al. (1982) assumed that an equivalence class, especially a symmetrical relation, involves transforming a conditional discrimination into a semantic process. Then, they suggested that "if the assumption is valid, conditional discrimination would be a procedural model for studying aspects of language even in nonhuman animals" (Sidman et al., 1982, p. 24).

To investigate this possibility, Sidman et al. (1982) searched for symmetrical relations between sample and comparison stimuli, not only with children but also with baboons and rhesus monkeys. The majority of children demonstrated symmetry in the conditional discrimination. However, monkeys and baboons did not show any proof of symmetry and transitivity. As Hogan and Zentall (1977), Holmes (1979), and Rodewald (1974) had already reported the absence of symmetry with pigeons, Sidman et al. (1982) concluded that proof of an equivalence class between sample and comparison stimuli for monkeys, pigeons, or baboons remains to be provided because symmetry and transitivity are necessary properties of an equivalence class.

After Sidman et al. (1982), many studies were conducted to investigate the possibility of symmetry in non-human animals, and confirmed the absence of symmetry in non-human animals when they are trained and tested in matching-to-sample (D’Amato, Salmon, Loukas, \& Tomie, 1985; Dugdale \& Lowe, 2000; Gómez, García, \& Pérez, 2014; Lionello-DeNolf \& Urcuioli, 2002; Lipkens, Kop, \& Matthijs, 1988; Meehan, 1999; Richards, 1988; Tomonaga, Matsuzawa, Fujita, \& Yamamoto, 1991; Yamamoto \& Asano, 1995; for a review, see Lionello-DeNolf, 2009), although there are some exceptions (e.g., McIntire, Cleary, \& Thompson, 1987; Schusterman \& Kastak, 1993; Tomonaga et al., 1991; Velasco, Huziwara, Machado, \& Tomanari, 2010) that used special matching-to-sample procedures.

The reason it was so difficult to obtain proof of symmetry in non-human animals has been discussed. Sidman et al. (1982) inferred the following two possibilities. One is the lack of relevant experience of 
symmetry in non-human animals. Ordinarily, pigeons, monkeys, and baboons, unlike humans, might not experience enough exemplars for them to appreciate the concept of symmetry. The other possibility is the procedural obscurity of matching-to-sample in appreciating the functional classes of sample and comparison. Unless these functional classes required for symmetry have been established, symmetry will not be confirmed. Sidman et al. (1982) suggested that the matching-to-sample procedure "may have obscured the functional classes by confining the potential members of each class to particular locations on the key matrix..." (p. 43). In this case, as Sidman et al. (1982) suggested, "incorrect specification by the experimenter of the controlling stimuli in the conditional discriminations may be the most fundamental factor underlying the absence of symmetry" (p. 43). Furthermore, they suggested the possibility of ethological invalidity of the stimuli and their biological functions in their procedure.

When we find any differences between humans' and non-human animals' behaviors, we usually attribute these to differences in certain cognitive abilities or to differences in species-specific behaviors (cf. Hinde \& Stevenson-Hinde, 1973). As Urcuioli (2015) suggested, we might infer that human language abilities not found in non-human animals are responsible for the emergence of symmetry. Devaney, Hayes, and Nelson (1986), Hayes (1989), and Horne and Lowe $(1996$; 1997) proposed the possibility as an issue of naming (for details, see the general discussion section in this paper).

However, Sidman et al. (1982) suggested a thorough analysis of failures of the procedure to generate symmetry. Furthermore, Sidman (1987) claimed that "attention to methodology is a prerequisite both for valid research and for effective application" (p. 11). Furthermore, Sidman (2000) claimed that equivalence is a direct outcome of reinforcement contingencies for humans and non-human animals. In response to Sidman et al. (1982) and Sidman (1987; 2000), Urcuioli (2015) argued that the lack of evidence of symmetry in non-human animals may not be attributable to linguistics but to methodology.

In fact, Lionello and Urcuioli (1998) suggested that the two-alternative choice matching-to-sample procedure used in most previous studies is inadequate for investigating pigeons' symmetry, because the spatial location of each matching stimulus is the functional matching stimulus for pigeons (see also Lionello-DeNolf \& Urcuioli, 2000). In a two-alternative choice matching-to-sample, usually the sample stimulus appears on the center key of the operant chamber and the comparison appears on either side key. Thus, the location of each stimulus differs between the sample and the comparison, even if the nominal properties of each stimulus are the same, as the spatial location of each matching stimulus is different, and the sample and the comparison are different for pigeons.

Lionello-DeNolf and Urcuioli (2002) devised a procedure (multiple-location training) to reduce or eliminate control by the location of each matching stimulus. However, even though they used the procedure, they did not observe symmetry for pigeons, and speculated that the temporal components associated with sample presentation are another potential disturbing variable for symmetry. In the typical matching-to-sample procedure, the sample always appears first, and the comparison always appears second. If the temporal/ordinal factor is an aspect of the functional stimuli for pigeons, the temporal order of the two stimuli would be another impediment to symmetry.

Based on this speculation, Frank and Wasserman (2005, Experiment 1) and Urcuioli (2008, Experiment 3) used successive (go/no-go) matching rather than n-alternative matching as the training and testing paradigm for pigeons' symmetry and provided evidence for symmetry in some pigeons. In the successive matching procedure in Urcuioli (2008, Experiment 3), the single sample stimulus in each trial is followed by a single 
comparison stimulus presented in the same spatial location. In his study, each stimulus was presented for approximately $5 \mathrm{~s}$ with a short inter-stimulus interval separating the sample from the comparison. Some sample-comparison sequences ended with reinforcement for the first response to occur after the comparison-stimulus interval. Other sequences ended without reinforcement. The reinforced and non-reinforced trials were equally arranged for each matching. The stimuli used were red, green, a triangle, or three horizontal lines on the key of the operant chamber. Each stimulus was presented as a sample or a comparison.

As baseline tasks in Urcuioli (2008, Experiment 3), three successive matching tasks - AB (arbitrary) matching, AA (hue identity) matching, and $\mathrm{BB}$ (form identity) matching-were trained. In the sample-comparison sequences of the arbitrary matching, a color sample was followed by a form comparison. In two identity matchings, nominal features of the comparison were the same as the sample. That is, in the hue identity matching, a red sample was followed by a red comparison or a green sample was followed by a green comparison. In the form identity matching, a triangle was followed by a triangle or three horizontal lines were followed by horizontal lines.

Pigeons were concurrently trained to ensure high levels of discriminative performance on the three successive tasks. The conditional discrimination performance (a discrimination ratio; DR) was computed by dividing the total number of comparison pecks on reinforced trials by the total number of comparison pecks on both reinforced and non-reinforced trials. Once a pigeon's performance on all three baseline tasks met the criterion (DRs $\geq 0.80$ for five of six consecutive sessions, plus 10 subsequent overtraining sessions), testing commenced with non-reinforced BA (symmetry) probe trials intermixed among all of the various baseline trials (for details, see Urcuioli, 2015). The results were that pigeons pecked more on the symmetry (BA) positive probes that were the reverse of the reinforced baseline $(\mathrm{AB})$ relations than on negative probes that were the reverse of the non-reinforced baseline (AB) relations. Urcuioli (2008, Experiment 3) found that three of seven pigeons demonstrated symmetry.

Urcuioli (2008) formalized his unique theory of pigeons' stimulus class formation. His and his colleagues' studies verified his theory (e.g., Sweeney \& Urcuioli, 2010; Urcuioli, 2008; Urcuioli \& Swisher, 2015, Experiment 1). Urcuioli (2015) concisely and clearly explained his theory. The theory is based on four major assumptions of pigeons' stimulus class formation. The first assumption is that "the functional matching stimuli in pigeons' successive matching are compounds consisting of the nominal stimulus and when it appears in a matching trial (viz., first (as a sample) or second (as a comparison))" (Urcuioli, 2015, p. 14, Table 2). The second assumption is that "the continuous juxtaposition of non-reinforced with reinforced sample-comparison combinations in successive matching facilitates stimulus class formation" (Urcuioli, 2015, p. 14, Table 2). The third assumption is that "stimulus classes consist of the elements (the functional matching stimulus) of the reinforced trials" (Urcuioli, 2015, p. 14, Table 2). The final assumption is that "elements common to more than one stimulus class cause their respective classes to merge" (Urcuioli, 2015, p. 14, Table 2).

Urcuioli's theory predicts not only symmetry but also anti-symmetry for pigeons. Although symmetry is based on the hue identity matching, anti-symmetry is based on the hue oddity matching, and pigeons respond more to the comparisons on negative than on positive BA probe trials. In fact, Urcuioli and Swisher (2012) showed evidence of anti-symmetry in pigeons. Urcuioli's theory successfully predicted all three derived relations that Sidman and Tailby (1982) proposed as criteria for stimulus equivalence: reflexivity, symmetry, and transitivity (Sweeney \& Urcuioli, 2010; Swisher \& Urcuioli, 2018; Urcuioli \& Swisher, 2015). Findings from a series of his studies confirmed the prediction of Urcuioli's theory and have demonstrated some 
never-before-seen emergent effects such as anti-symmetry and anti-transitivity in pigeons (for more details, see Urcuioli, 2015).

Urcuioli's theory (2008), as Urcuioli (2015, p. 21) concluded, supports Sidman's (1994; 2000; 2008) theory, which claims that equivalence class is a direct outcome of reinforcement contingencies. Sidman (2000) and Sidman et al. (1982) consistently emphasized the importance of experimental methodology. Sidman (2000) claimed that "for me, methodology and theory are inseparable" (p. 131) and that "methodology rears its ugly head, raising questions that have priority over theory" (p. 145). As Urcuioli and his colleagues' studies shifted from n-alternative matching to a successive matching procedure and yielded robust proof of symmetry, we believe that Urcuioli's theory certainly supports Sidman's claim.

Considering this, is it possible for Urcuioli's theory to explain not only pigeons' but also humans' symmetry? Unfortunately, Urcuioli does not clearly describe an extension of his theory to human behavior (see Swisher \& Urcuioli, 2015, p. 131). As long as he supports Sidman's (2000) theory, Urcuioli's theory should also explain symmetry in humans because Sidman (2000) does not distinguish between human derivation processes of emergent relations and those of non-human animals. Sidman (1990; 1994; 2000) consistently claimed that equivalence relations arise directly from the reinforcement contingency and claimed that "accurate prediction of which nonhumans - or even humans - can and cannot show equivalence relations, far from diminishing the theory, will increase its breadth" (Sidman, 2000, p. 145, italics added). To support Sidman's claims, Urcuioli's theory should explain human stimulus class formation in a successive matching procedure.

Not only to support Sidman's claims but also to comprehend controlling variables for stimulus class formation, Urcuioli's theory should explain human stimulus class formation because our behavior is a function not only of concurrent contingencies but also successive ones. Fortunately, inspired by Urcuioli's theory (2008), Beurms, Traets, De Houwer, and Beckers (2017) and Fagot, Malassis, and Medam (2017) investigated human symmetry formation in a successive matching task. Both studies found functional symmetry is demonstrated in humans. Beurms et al. investigated symmetry in undergraduate students in a modified successive matching procedure by using stimuli that were not easily nameable and found that the participants readily demonstrated not only symmetry but also anti-symmetry based on physical properties of the stimuli, independently of the spatial and temporal location of the stimuli. Fagot et al. compared symmetry formation between adults at their university and baboons. Their task was a serial reaction time task to test whether the participants responded based on matching relations (i.e., symmetry demonstration) or spatial location of the stimuli (visual shapes on a touch screen). Furthermore, they asked human participants to verbally report their understanding of the task after the test phase. From this interview, they divided human participants into two groups: a group who conducted labeling for the stimuli and a group who did not. The findings of their experiment were that human participants who used labels to code the stimuli demonstrated symmetry but humans who did not use labels, and baboons, did not demonstrate symmetry, and that baboons responded based on the stimuli's spatial location. From these results, with reference to verbal communication in humans, Fagot et al. suggested the necessity of understanding the effect of labeling on stimulus class formation in a successive matching task.

From the above two studies that used successive matching procedures for humans, we can find that humans also demonstrate symmetry in the procedure. However, this is not to say that they did not discuss their own findings from the four assumptions of Urcuioli's theory, but that they focused on functional stimuli for symmetry for humans. Furthermore, although Fagot et al. (2017) investigated the relationships between human verbal behavior and demonstration of symmetry and insisted on the necessity of further investigation of the 
effects of labeling (i.e., naming), Beurms et al. (2017) did not address the issue about naming involvement in symmetry formation.

Therefore, the present study was designed to investigate whether successive matching procedures could produce symmetry in human participants. As naming is thought to be a crucial variable for emergent relations in humans (Horne \& Lowe, 1996), at the end of the experiment, we investigated participants' verbal behavior that might be displayed during successive matching. To do so, we used the same stimuli as those in Urcuioli (2008), which were easy stimuli for humans to label. Finally, we will discuss the results of our study in terms of the four assumptions of Urcuioli's theory and the significance of Urcuioli's theory in terms of our findings.

We conducted two experiments for this purpose. Although each experiment's procedure was similar to Urcuioli's procedure, we modified the procedure for our human participants. The present study received ethical approval by the ethical review board of the graduate school of our university.

\section{Experiment 1}

This experiment aimed to investigate whether undergraduate students could form symmetry by a successive matching procedure similar to that of Urcuioli (2008, Experiment 3); to examine the possibility of naming matching stimuli; and to observe participants' strategy to learn conditional discriminations.

\section{Method}

Participants. Four students (two females and two males) in an undergraduate program in psychology at our university, with ages ranging from 20 to 22 years $(M=20.25, S D=0.50)$, participated in this experiment. Prior to participation, they gave written informed consent.

Setting, apparatus, and stimuli. This experiment was conducted in a sound proof room consisting of two cubicles, one for the participant and the other for the experimenter. Each participant sat in front of a 10.1-inch liquid-crystal touch screen $(12.7 \mathrm{~cm}$ by $22.4 \mathrm{~cm})$ that detected the participant's responses and a speaker though which the participant received a feedback tone about their performance. The screen and the speaker were connected to a notebook computer that controlled the presentation of stimuli and recorded the participant's responses on each trial, using a program written in Visual Basic 2010.

Stimuli were essentially the same as those used in Urcuioli (2008, Experiment 3). Although Urcuioli used red and green homogenous fields, an inverted triangle on a black background, and three horizontal white lines that were projected onto the pigeon's key $(2.5 \mathrm{~cm}$ in diameter), we used different sized stimuli for human participants. The form of the red and green stimuli was a circle $(5 \mathrm{~cm}$ in diameter) and the color of the inverted triangle and three horizontal lines was black. The stimuli were presented on a white background on the touch screen. The height of the inverted triangle was $3.4 \mathrm{~cm}$, and the length of base of the triangle was $3.8 \mathrm{~cm}$. The length of the middle line of three horizontal lines was $5 \mathrm{~cm}$, and the length of the other two lines was $3.4 \mathrm{~cm}$. The width of each line was $0.2 \mathrm{~cm}$ and the interval of each line was $1.7 \mathrm{~cm}$. The area sensitive to the participant's response was the circle $(5 \mathrm{~cm}$ in diameter) on the panel, and all stimuli were projected into this area. When the participants responded to a respective stimulus (sample and comparison), they had to touch the area with a touch pen.

Procedure. The present experiment consisted of two phases: baseline and test phases. In the baseline phase, successive matching training was conducted in each session per day. In the test phase, two test sessions were conducted to investigate whether each participant formed symmetry. 
Before the baseline phase began, each participant sat in front of the touch screen and received the following instructions (translated from Japanese) from the experimenter (the first author of this paper):

You can see the word "Start" on the touch screen in front of you. If you are ready to begin the experiment, please touch the "Start" button with the touch pen. The experiment will now start. At the same time, you can see the first stimulus on the screen with a blip. After watching the stimulus, please touch the stimulus with the pen. When you touch the stimulus, the stimulus will disappear and then another stimulus will appear at the same place with two blips. Please watch the second stimulus. After that, you can choose to touch or not touch the stimulus. If you touch the second stimulus, sometimes you can get your score cumulatively with the pips. But your cumulative score will not be shown on the screen. After that, the second stimulus will disappear. When you either don't touch the stimulus or you cannot get any score even if you touch the stimulus, the second stimulus will disappear after a short time. In either case, after the second stimulus disappears, the screen will go blank for a while, and then the first trial will end and the second trial begin. The procedure will be repeated. The procedure of each trial is the same. However, in some trials the stimuli on the screen are the same and in other trials they are different. The duration of each session is about 40-50 min. You will receive one session per day. Possibly, all experimental sessions will end within a week. Depending on your cumulative score, you can get book coupons. Please score as much as you can.

After the instruction, the participant began concurrent training on symbolic (hue-form), hue-identity, and form-identity successive matching. Each trial began with the onset of the sample stimulus on the screen. During the presentation of the stimulus, a fixed ratio 1 (i.e., FR 1) schedule was in effect. That is, if the participant watched the stimulus and then touched it once, the stimulus disappeared. After a $1 \mathrm{~s}$ blank interval, the second stimulus appeared as the comparison stimulus at the same place on the screen. During the presentation of the comparison stimulus, a variable interval 10-s (i.e., VI 10-s) schedule was in effect. This schedule was used to make participants respond to the stimulus constantly. For reinforced sample-comparison combinations, the first response after the VI value produced the offset of the stimulus and the cumulative score with the pips. However, the cumulative score was not shown on the screen. Only the pips were presented as a conditioned reinforcer because if the participant responded constantly during the presentation of the comparison stimulus on all reinforced trials, he or she would always receive a fixed cumulative score in all sessions. Then, the participant's responding might not be under the contingencies of reinforcement when the participant knows he or she would obtain a fixed cumulative score in all sessions. The comparison stimulus remained unchanged on reinforced trials until the participant responded. When the participant touched the screen after the variable interval on reinforced trials, the response was reinforced with the pips and then the trial ended. For non-reinforced sample-comparison combinations, the stimulus disappeared after the variable interval without reinforcement. The inter-trial interval was $3 \mathrm{~s}$, during which there were no stimuli on the screen. For all participants, on the hue identity matching trials, touching the red comparison after a red sample and the green comparison after a green sample were reinforced. On the form identity matching trials, touching the triangle comparison after a triangle sample and the horizontal comparison after a horizontal sample were reinforced. On the symbolic matching trials, for two participants, touching the triangle comparison after the red sample and the horizontal comparison after the green sample produced the pips as a conditioned reinforcer, whereas touching the triangle comparison after the green sample and the horizontal comparison after the red sample were non-reinforced. For the remaining two participants, the opposite contingencies were in effect. Each training session contained 32 trials, each of hue identity, form identity, and symbolic matching trial. Each of the four possible combinations of samples and comparisons of each task occurred eight times in random order in each session so that the same trial and reinforced or non-reinforced trial were not presented more than three times consecutively. The total 
duration of the comparison stimulus on reinforced trials was almost $80 \mathrm{~s}$, which was equal to that of the comparison stimulus on non-reinforced trials. Urcuioli (2008) continued the baseline phase until their pigeons' discrimination ratio (DR) achieved their criterion of discrimination acquisition. His criterion of acquisition was that a DR should be 0.80 or higher on each matching task for 5 of 6 consecutive training sessions. In the present experiment, however, due to our participants' personal circumstances, the number of sessions of the baseline phase was four or five even if their DRs failed to meet Urcuioli's criterion. Two participants received four sessions and the remaining two participants did five sessions.

After the baseline phase, the test phase consisting of two sessions was conducted. Before the test sessions, each participant received the following further instruction.

Today's experimental procedure is almost the same as the previous one. However, in this experiment, there are no pips when you get a score. And in the same way as the previous one, your cumulative score will not be shown on the screen on all trials. However, as your score is recorded in the computer, please score as much as you can.

Each test session contained 96 non-reinforced matching baseline trials and eight non-reinforced symmetry probe trials. The matching baseline trials were the same as those in the baseline phase sessions except that the matching baseline trials in the test sessions were non-reinforced ones. The symmetry probe trials consisted of a triangle or horizontal sample followed by a red or green comparison. The four possible combinations of the form samples with the hue comparisons occurred equally often in each session. The duration of the comparison presentation on the symmetry probe trials was $10 \mathrm{~s}$. However, on the matching baseline trials, the duration of the comparison presentation was $10 \mathrm{~s}$ on average because the duration of the comparison presentation on the matching baseline trials was determined based on variable intervals.

After the second test session, each participant was debriefed about the experiment by the experimenter, who asked participants to answer the following five questions to investigate their awareness of the present experiment and the possibility of naming sample-comparison combinations.

1. Please report whatever you know about the experiment.

2. Do you think you obtained a high score?

3. Did you know how you could get the score?

4. What did you think about the last two sessions?

5. Did you measure how long it took for something to happen? If you timed it, how did you do so?

After the debriefing, each participant received information about the present experiment. Although the participants had been informed in the first instruction that they could receive book coupons depending on their cumulative score, they received a fixed number of book coupons in return for their participation because the number of reinforced trials was the same among all participants. We apologized to them for the deception and offered the reason for this and obtained their understanding.

\section{Results and Discussion}

Figure 1 shows the average response rate (in touches/s) during the comparison stimulus presentation on reinforced and non-reinforced trials of three kinds of matching tasks in each session of the baseline phase for each of the four participants (PA1, PA2, PA3, and PA4). The average response rate on the reinforced trials was calculated based on the number of touches to the comparison stimuli within the interval set for the VI schedule in each reinforced trial. In the first session, two participants (PA1 and PA3) did not show any differentiation of 
responding. Other participants (PA2 and PA4) responded more on reinforced than on non-reinforced trials in the first session. The response rates of two participants (PA2 and PA4) on reinforced trials increased over the sessions while those on non-reinforced trials decreased, and their rates of responding were clearly differentiated in the last two sessions. PA3 showed weak differentiation of responding in each of the last two sessions. PA1 did not show any differentiation of responding over four sessions. The DRs of each participant for each of three kinds of matching tasks in the last session of the baseline phase were computed in the same way as Urcuioli's (2008). The DRs of each participant for symbolic, hue-identity, and form-identity matching were $0.51,0.37$, and 0.58 for PA1, 1.0, 1.0, and 0.95 for PA2, 0.69, 0.89, and 0.87 for PA3, and 0.96, 0.92, and 0.98, for PA4, respectively.
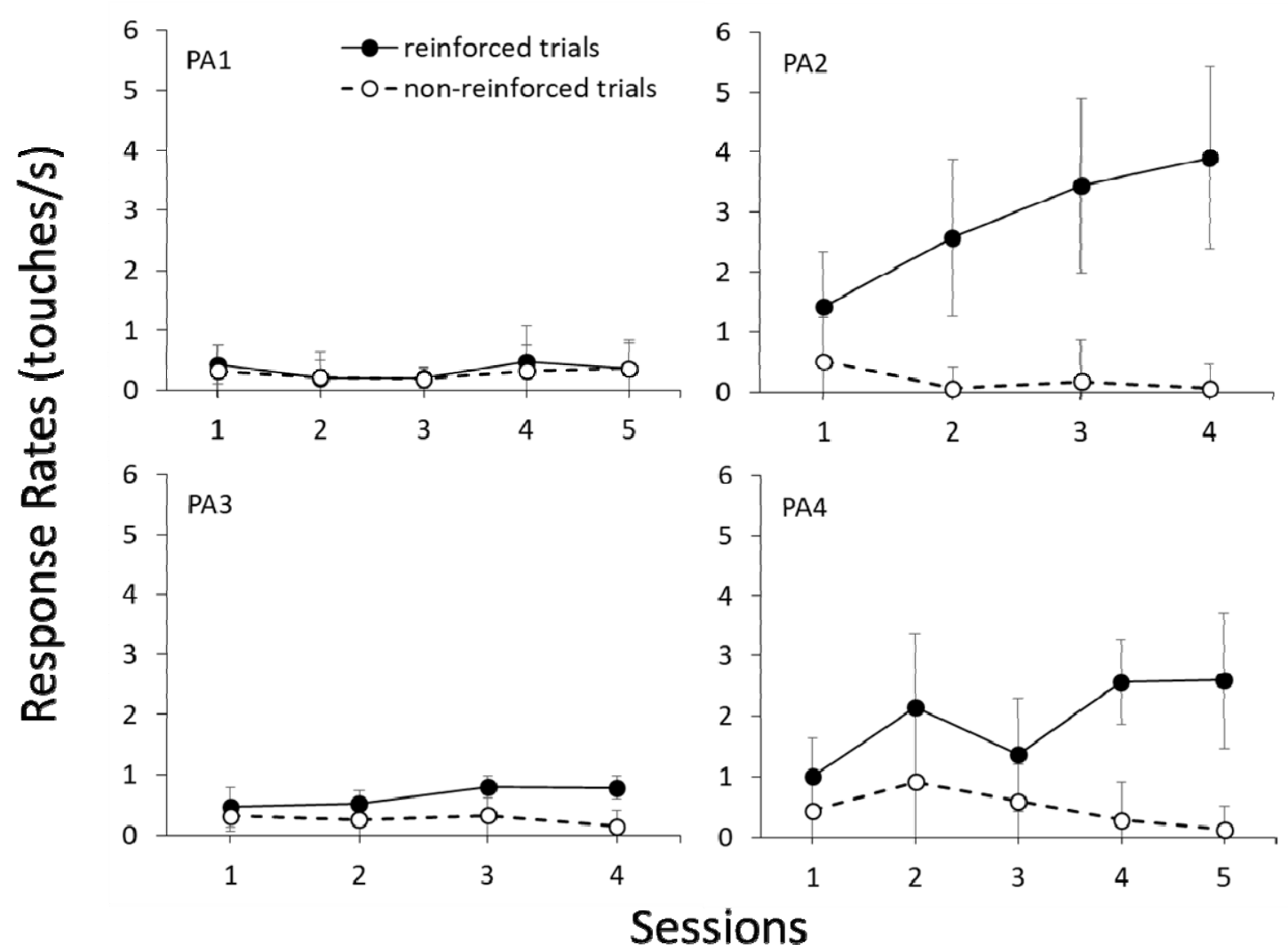

Figure 1. The average response rates (in touches/s $\pm \mathrm{SD}$ ) during the comparison stimulus presentation on reinforced and non-reinforced trials of three kinds of matching tasks (hue identity, form identity, and symbolic matching) in each session of the baseline phase for each participant (abbreviations for each participant: PA1, PA2, PA3, and PA4).

Figure 2 presents individual-participant data averaged over two test sessions. Using the same presentation format as Frank and Wasserman (2005) and Urcuioli (2008), we showed solid and open circles for the comparison response rates (in touches/s) on symmetry probes and on the symbolic matching baseline trials, respectively. The solid circles plot the average comparison response rates on symmetry probes that were the reverse of the reinforced symbolic baseline trials ("positive") and the reverse of the non-reinforced symbolic baseline trials ("negative"). Open circles plot the average comparison rates on the positive and negative trials over two test sessions. The sample-comparison combinations on the positive trials were the same as those on the reinforced symbolic matching baseline trials and the sample-comparison combinations on the negative trials 
were the same as those on the non-reinforced symbolic matching baseline trials. As all participants' responding on all trials of each test session were under non-reinforcement, we could not use the terms "reinforced" and "non-reinforced".

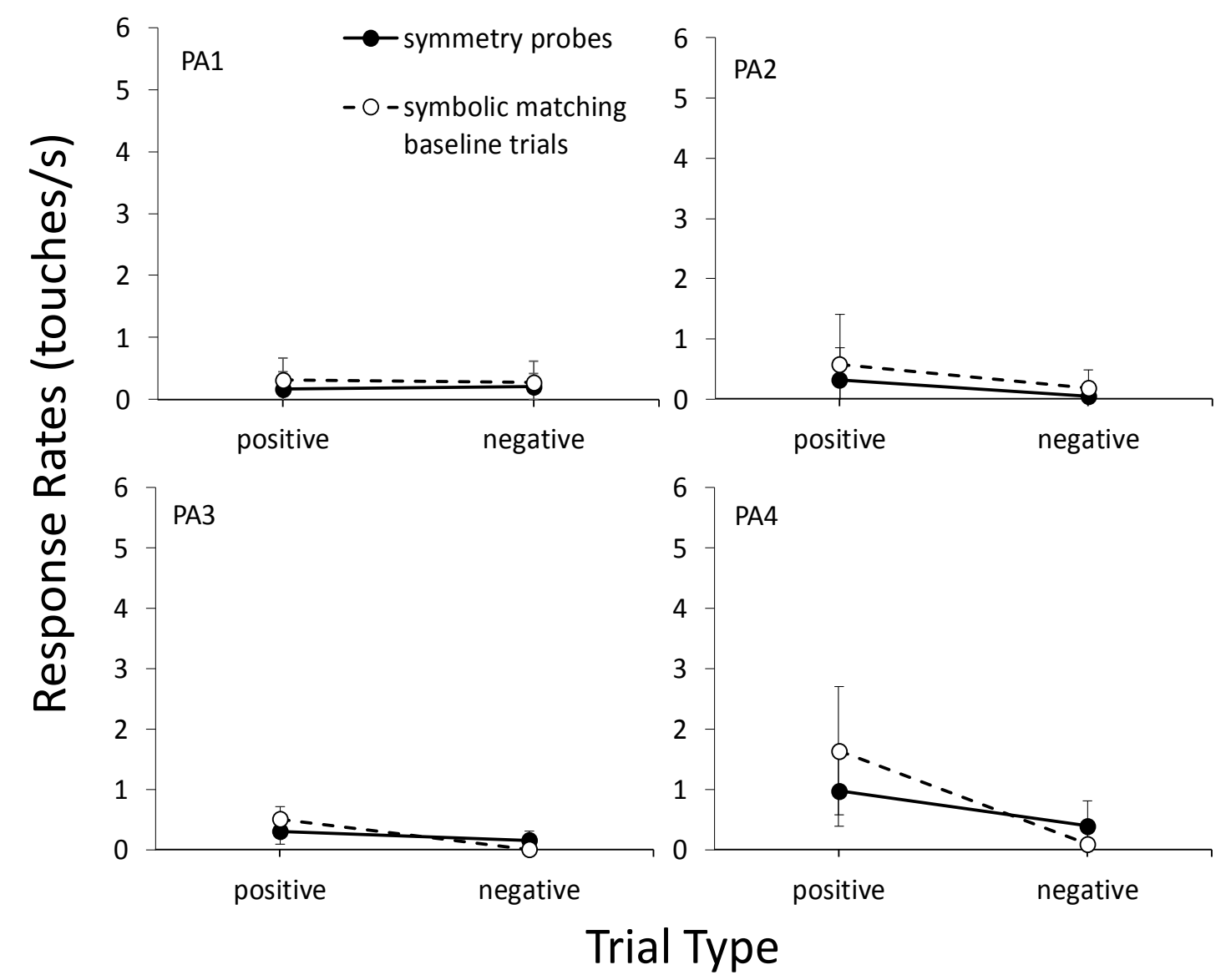

Figure 2. Comparison responses/s $( \pm \mathrm{SD})$ for each participant averaged over two test sessions. The solid circles plot the average comparison response rates on symmetry probes that were the reverse of the reinforced symbolic baseline trials ("positive") and the reverse of the non-reinforced symbolic baseline trials ("negative"). Open circles plot the average comparison rates on the positive and the negative trials. The sample-comparison combinations on the positive trials were the same as those on the reinforced symbolic matching baseline trials and the sample-comparison combinations on the negative trials were the same as those on the non-reinforced symbolic matching baseline trials. All participants' responding on all trials of each test session were under non-reinforcement.

For symbolic matching baseline relations (open circles in Figure 2), two participants (PA2 and PA4) who demonstrated clear differentiation of responding in the baseline phase and PA3 who showed weak differentiation in the baseline phase responded more on positive trials than on negative trials in test sessions. Contrary to these results, PA1 did not show any differentiation of responding. The average rates of responding (in touches/s) on positive and negative symbolic matching baseline trials for each participant were 0.31 and 0.28 for PA1, 0.57 and 0.19 for PA2, 0.51 and 0.00 for PA3, and 1.64 and 0.09 for PA4, respectively. A Wilcoxon signed-rank test showed that the difference in the rates of responding between the positive and the negative trials was statistically significant for all participants except PA1 $(Z=2.15, d f=1, p<0.05$ for PA2; $Z$ $=4.94, d f=1, p<0.01$ for PA3; $Z=4.66, d f=1, p<0.01$ for PA4). The results of the symbolic matching 
baseline relations showed that our participants maintained the same patterns of responding in the test phase as those in the baseline phase.

On symmetry probes (solid circles in Figure 2), only PA4's comparison-response rate was much higher on the positive symmetry probes than on the negative symmetry probes. The average rates of responding (in touches/s) on the positive and the negative symmetry probe trials for each participant were as follows: 0.18 and 0.21 for PA1, 0.31 and 0.05 for PA2, 0.30 and 0.15 for PA3, 0.98 and 0.40 for PA4. A Wilcoxon signed-rank test showed that for PA4 only, the difference in the rates of responding between the positive and negative trials was statistically significant $(Z=2.11, d f=1, p<0.05)$.

From the results of the baseline phase and those of both the symbolic matching baseline trials and the symmetry probe trials of the test phase, only PA4, who showed a clear differentiation of responding during the baseline phase, demonstrated such symmetry as defined by Urcuioli (2008). Although PA2 showed clear differentiation of responding and PA3 showed weak differentiation during the baseline phase, they did not demonstrate symmetry. PA1 who did not show any differentiation of responding did not show symmetry.

As symmetry is an emergent relation based on conditional discrimination by differential reinforcement, two participants (PA1 and PA3), who did not show clear differentiation of responding during the baseline phase, did not demonstrate symmetry, as expected. The fact that PA1 and PA3 did not show clear differentiation of responding might be due to their extreme low rates of responding on reinforced trials during the baseline phase. The low comparison-response rates for PA1 and PA3 on reinforced trials during the baseline phase might be because the pips were a weak reinforcer for them. However, as described below, PA1's low rate of responding would be due rather to this participant's strategy of responding. The issue will be discussed later.

PA2 showed clear differentiation of responding during the baseline phase and barely maintained differentiation on symbolic matching baseline trials during the test phase. Nevertheless, PA2 did not demonstrate symmetry on symmetry probes. PA2's DRs for symbolic, hue-identity, and form-identity matching in the baseline phase were very high $(1.0,1.0$, and 0.95 , respectively). However, in the test phase, those for the three matching tasks decreased $(0.71,0.75$, and 0.80 , respectively). The decrease in PA2's DRs was due to a decrease in rates of responding on positive symbolic matching baseline trials over the two test sessions. Although PA2's comparison-response rate on reinforced symbolic matching baseline trials in the last session of the baseline phase was 4.23 , the rate decreased on positive symbolic matching baseline trials in each test session to 0.45 in the first test session and 0.69 in the second test session. The differences in the rate between the last baseline session and each test session were statistically significant $(Z=3.516, d f=1, p<0.001$ for both test sessions). Thus, the reason PA2 did not demonstrate symmetry might be the significant decrease in the comparison-response rates on positive symbolic matching baseline trials in the two test sessions. Furthermore, the decrease in rates of responding might be due to non-reinforcement in each test session, which was different from Urcuioli's procedure (2008) in which the test session contained reinforced and non-reinforced trials.

Because all participants did not know their cumulative score during the training and the test sessions, their responding might not have received enough reinforcement on each reinforced trial (there was only one reinforcement on each reinforced trial) during the baseline phase. Insufficient opportunities for reinforcement during the baseline phase might have been responsible for the results of this experiment. If so, we need to increase opportunities for reinforcement on each reinforced trial in the baseline phase for development of conditional discrimination. 
To interpret the results of this experiment, we need to investigate the possibility of naming by each participant. The stimuli used in this experiment were by no means difficult for our participants to attend to or to name. In fact, they mentioned the nominal properties of the stimuli in their replies to the questions after the experiment. In sum, for the last three questions related to the symmetry, PA2, PA3, and PA4 referred to the appearance of new sample-comparison combinations in the test phase. However, they did not clearly mention the relations between the new and the old combinations.

PA1 and PA2 reported that responding to the identity matching produced the pips in the baseline phase, and PA3 and PA4 reported that some responses to the identity and symbolic matching produced the pips in the baseline phase and that the pips depended on the stimulus combination. PA1 reported that he attended only to the comparison stimuli. Furthermore, PA1 referred to the duration of the comparison presentation and reported that he waited for about $15 \mathrm{~s}$ after the onset of each comparison stimulus and responded only if the stimulus remained, to be even after the waiting time passed. Therefore, PA1's low rate of responding on reinforced trials might be due to this response strategy.

Regarding the test phase, PA2 reported that some new sample-comparison combinations appeared and the comparison stimuli were presented for fixed times. From PA2's replies to the questions, the results of PA2 (who showed clear differentiation of responding but did not demonstrate symmetry) might not only have been due to low rates of responding in the test phase but also to PA2's timing of the duration of the comparison presentation. PA3 referred only to the new sample-comparison combinations in the test phase. PA4, who demonstrated symmetry, referred to new sample-comparison combinations and the temporal order of the combinations. However, PA4 did not clearly state that she responded based on the temporal order.

Then, all participants in this experiment knew which sample-comparison combinations produced the pips for their responding during the baseline phase. However, for the test phase, they referred only to the appearance of new sample-comparison combinations. Although PA4 referred to the temporal order of sample-comparison combinations, she did not clearly state the relation between the new and old combinations. All participants except PA1 did not state their way of responding to the new sample-comparison combinations. PA1 attended only to the comparison stimuli and responded by his own rule, regardless of the relations between stimuli.

Thus, our participants' performance in the test phase was possibly a result of the contingencies of reinforcement in successive matching rather than naming the stimulus relations. Therefore, we might say that successive matching in the present experiment could produce symmetry for humans. However, the evidence was not sufficient because the only participant who demonstrated symmetry was PA4. We need further procedural improvements to facilitate differentiation of responding in the baseline phase.

In this experiment on reinforced trials in the baseline phase, each comparison stimulus remained to be presented until the participant responded after the variable interval. The variable interval might have led to differences in comparison-response rates among our participants. Furthermore, on non-reinforced trials, each comparison stimulus automatically disappeared after at least $3 \mathrm{~s}$ from the onset of the comparison stimulus. This might have made our participants respond less than on reinforced trials because they tried to wait for at least $3 \mathrm{~s}$. In fact, PA1 applied this waiting strategy during the comparison stimulus presentation. Therefore, we should make the duration of comparison presentation constant. Moreover, the participants' responding should be reinforced several times on reinforced trials during the comparison stimulus presentation to increase their rates of responding. Furthermore, we should promote the opportunity that participants monitored the sample stimulus closely because PA1 reported paying attention to the comparison stimuli only. The next experiment 
was conducted to investigate the same issues as the present experiment by changing contingencies of reinforcement in a successive matching procedure.

\section{Experiment 2}

This experiment aimed to investigate whether undergraduate students could demonstrate symmetry by a successive matching procedure that promotes differentiation of responding during the baseline phase and to investigate relationships between the participants' derivation processes of symmetry and their naming of sample-comparison combinations.

\section{Method}

Participants. Five new students (four females and one male) in an undergraduate program in psychology at our university, with ages ranging from 20 to 22 years $(M=20.20, S D=0.45)$, participated in this experiment. Prior to participation, they gave written informed consent.

Setting, apparatus, and stimuli. The experimental setting, apparatus, and stimuli in this experiment were the same as those of the previous experiment (Experiment 1).

Procedure. The present experiment also consisted of two phases: baseline and test phases. In the baseline phase, successive matching training was conducted. In the test phase, two test sessions were conducted to investigate whether each participant could demonstrate symmetry. We arranged the number of sessions per day per the convenience of each participant, with a limit of three sessions per day for each participant.

The instruction before the beginning of the baseline phase was almost the same as that in the previous experiment. After the instruction, the participant began concurrent training on symbolic (hue-form), hue-identity, and form-identity successive matching. The procedure in the baseline phase was almost the same as that in Experiment 1, except for the schedules during the sample and the comparison periods and the constant duration of the comparison stimulus presentation. A fixed ratio (FR) schedule was in effect during the sample stimulus presentation and a fixed interval (FI) was in effect during the comparison stimulus presentation. The presentation interval of each comparison stimulus was also fixed. An FR during the sample stimulus presentation was used to promote the opportunity that participants monitored the stimulus closely. An FI during the comparison stimulus presentation was used so that participants' responding was reinforced many times during the presentation of the comparison stimulus.

Each trial began with the appearance of the sample stimulus on the screen. During the stimulus presentation, an FR3 schedule was in effect. When the participant watched the stimulus and then touched it three times, the stimulus disappeared. After a $1 \mathrm{~s}$ blank interval, the second stimulus appeared as the comparison stimulus at the same place on the screen. The duration of the comparison stimulus presentation was a constant $20 \mathrm{~s}$ during which an FI schedule was in effect to facilitate participants' responding on reinforced trials; the comparison stimulus remained unchanged for $20 \mathrm{~s}$ on reinforced trials. The FI values were either 4-s, 5-s, 7-s, 9-s, or 10-s. Each value was set for each reinforced trial; the value was different in reinforced trials. For example, in reinforced trials under FI 4-s, the participant could score four times at most during the comparison stimulus presentation. In this way, participants' responding could be reinforced many times during the comparison stimulus presentation on reinforced trials. The FI value in each reinforced trial was randomly determined except that the same value was set for each matching task. On reinforced trials, the first response after the FI value produced only the pips as a conditioned reinforcer and the comparison stimulus disappeared 
$20 \mathrm{~s}$ after the onset of the stimulus. On non-reinforced trials, the stimulus disappeared without the pips $20 \mathrm{~s}$ after the onset of the comparison stimulus. The inter-trial interval was $3 \mathrm{~s}$, during which there were no stimuli on the screen.

The tasks in the baseline phase were the same as those in Experiment 1, except for the number of trials in each session. Each training session in the present experiment contained 60 trials: 20 trials, each of hue identity, form identity, and symbolic matching. Each of the four possible combinations of samples and comparisons of each task occurred five times in random order in each session so that the same and reinforced or non-reinforced trial were not presented more than three times consecutively. The participants were informed about their cumulative score after the end of each session of the baseline phase. This information was an establishing operation that might increase the possibility of their responding.

The baseline phase contained five or six sessions because of the participants' personal circumstances even if their DRs failed to meet Urcuioli's criterion. Three participants received five sessions and the remaining two did six sessions.

The baseline phase was followed by the test phase consisting of two sessions. Before the test sessions, each participant received the same instruction as in Experiment 1. Furthermore, the test phase procedure was the same as in Experiment 1, except that there were 68 trials in each test session (60 symbolic matching baseline trials and eight non-reinforced symmetry probe trials) and the duration of the comparison stimulus presentation was $20 \mathrm{~s}$.

After the second test session, the experimenter asked participants to answer the following eight questions to investigate their awareness of the present experiment and the possibility of naming sample-comparison combinations. The second, fifth, sixth, and seventh questions were new questions to investigate the possibility of naming stimulus combinations by each participant.

1. Please report whatever you knew about the experiment.

2. Did you have any rules about whether you should touch the second stimulus?

3. Did you know how you could get a score?

4. What did you think about the last two sessions?

5. Did you know there were some trials containing new stimulus combinations during the last two sessions?

6. Did you know there were some trials that were the reverse of the temporal order of combinations of color and form?

7. How did you respond on the new trials?

8. Did you measure how long it took for something to happen? If you timed it, how did you do so?

After the debriefing, each participant received information about the present experiment and received a fixed number of book coupons for their participation in the present experiment in the same way as in the previous experiment.

\section{Results and Discussion}

Figure 3 shows the average response rates (in touches/s) during the comparison stimulus presentation on reinforced and non-reinforced trials for three kinds of matching tasks in each session of the baseline phase for each participant (abbreviations for each participant: PB1, PB2, PB3, PB4, and PB5). In the first session, participants did not show any differentiation of responding. However, they responded more on the reinforced than on the non-reinforced trials after the first, second, or third session. All participants responded more on the 
reinforced than on the non-reinforced trials over the last two sessions. Especially, the response rates of PB3 on the reinforced trials increased over the sessions while those on the non-reinforced trials decreased, and their rates of responding were clearly differentiated in the last three sessions. PB5 also showed clear differentiation of responding during the last two sessions. The other three participants (PB1, PB2, and PB4) showed relatively weak differentiation of responding. The DRs of each participant for symbolic, hue-identity, and form-identity matching in the last session of the baseline phase were $0.81,0.75$, and 0.91 for PB1, 0.98, 0.99, and 0.93 for PB2, and $0.85,0.93$, and 0.89 for PB3, respectively. The DRs of PB4 and PB5 for all matching tasks were 1.0. Then, the DRs of all participants in the last session were relatively higher than those of participants in the previous experiment. The higher DRs for the participants in this experiment and the demonstration of differentiation of responding by most participants might be due to the procedural change in the second experiment.

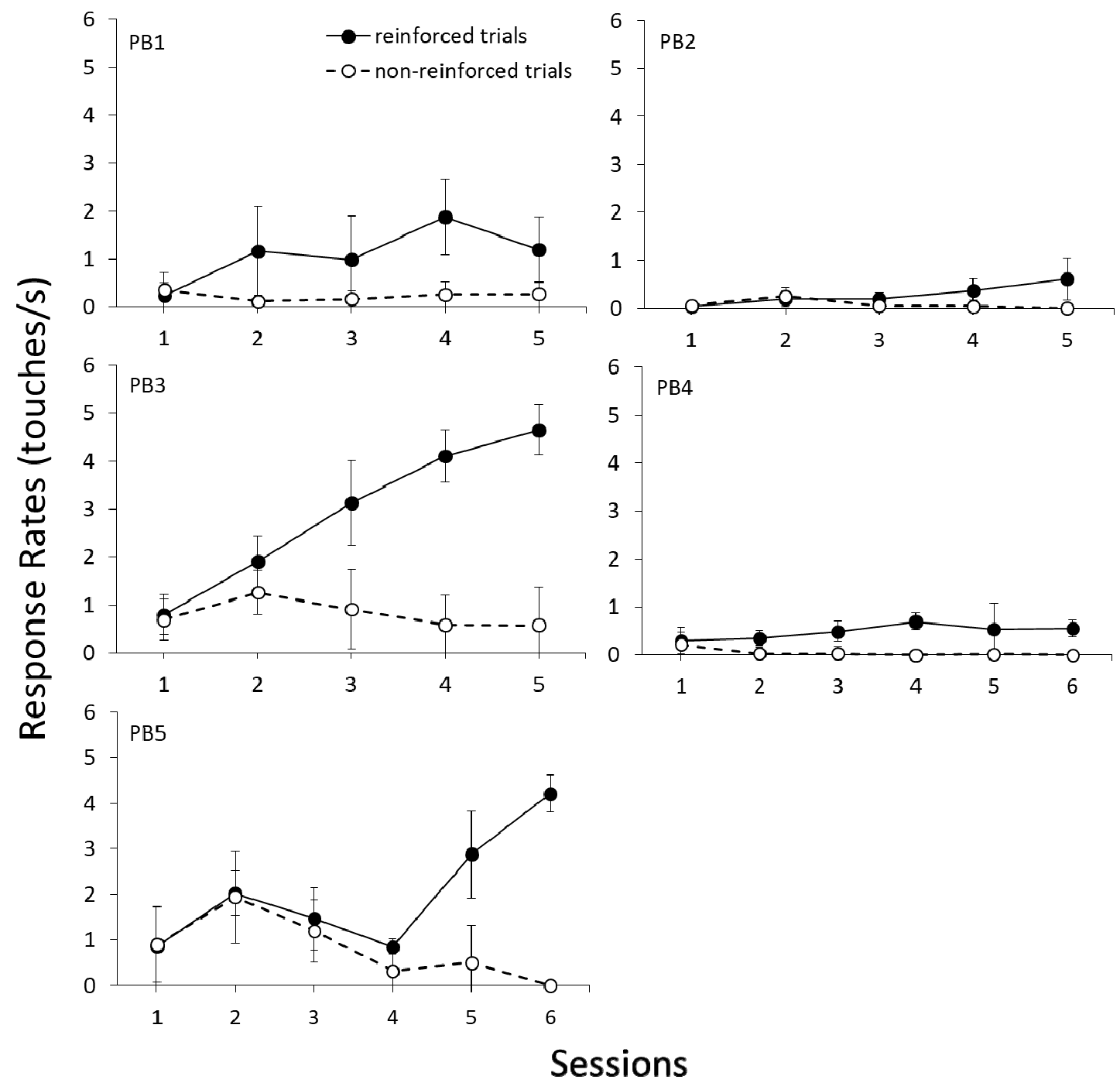

Figure 3. The average response rates (in touches/s $\pm \mathrm{SD}$ ) during the comparison presentation on reinforced and non-reinforced trials for three kinds of matching tasks in each session of the baseline phase for each participant (abbreviations for each participant: PB1, PB2, PB3, PB4, and PB5). 
Figure 4 presents individual-participant data averaged over two test sessions in the second experiment. The presentation format is the same as that of Figure 2.

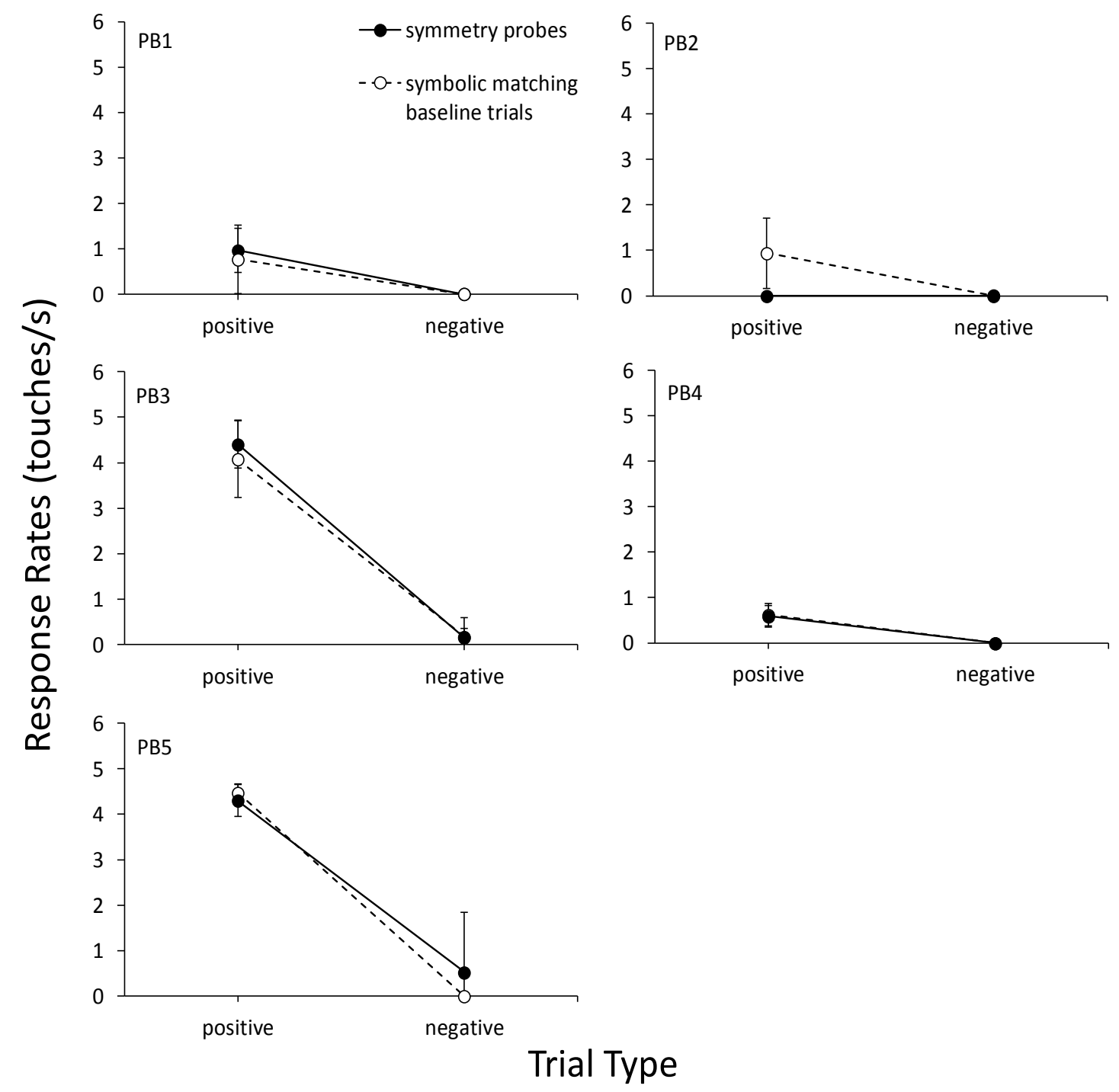

Figure 4. Comparison responses/s $( \pm \mathrm{SD})$ for each participant averaged over two test sessions. The presentation format is the same as that of Figure 2.

For symbolic matching baseline relations over the two test sessions (open circles in Figure 4), all participants responded more on positive than on negative trials in the test phase. The average rates of responding (in touches/s) on positive and negative symbolic matching baseline trials for each participant were 0.77 and 0.00 for PB1, 0.94 and 0.00 for PB2, 4.08 and 0.18 for PB3, 0.62 and 0.00 for PB4, and 4.48 and 0.00 for PB5, respectively. A Wilcoxon signed-rank test showed that the difference in the rates of responding between the positive and negative trials were statistically significant for all participants $(Z=3.92, d f=1, p<$ 0.01 for $\mathrm{PB} 1 ; Z=3.82, d f=1, p<0.01$ for $\mathrm{PB} 2 ; Z=3.88, d f=1, p<0.01$ for $\mathrm{PB} 3 ; Z=3.93, d f=1, p<0.01$ for PB4; $Z=3.93, d f=1, p<0.01$ for PB5). The results of the symbolic matching baseline relations showed that all participants maintained the same patterns of responding in the test phase as those in the baseline phase. 
On symmetry probes over the two test sessions (solid circles in Figure 4), the rates of responding (in touches/s) by all participants except PB2 were higher on the positive symmetry probes than on the negative symbolic probes. The average rates of responding (in touches/s) on the positive and on the negative symmetry probes for each participant except PB2 were 0.97 and 0.00 for PB1, 4.41 and 0.16 for PB3, 0.59 and 0.00 for PB4, and 4.30 and 0.53 for PB5, respectively. PB2 never responded on either the positive or the negative symmetry probes. A Wilcoxon signed-rank test showed that for all participants except $\mathrm{PB} 2$, the difference in the rates of responding between the positive and negative trials was statistically significant $(Z=2.52, d f=1, p$ $<0.05$ for all participants except PB2). From the results of both the symbolic matching baseline relations and the symmetry probes, all participants except PB2 demonstrated such symmetry as defined by Urcuioli (2008).

The procedural change that made differentiation of responding more likely during the successive matching training may explain the high percentage of participants who showed clear differentiation of responding during the baseline phase and the finding that all participants except PB2 demonstrated symmetry in the test phase. Therefore, the demonstration of symmetry by participants who showed clear differentiation of responding during the baseline phase might have been due to the contingencies of reinforcement of this experiment. However, verbal stimuli produced by our participants' verbal behavior to the sample-comparison combinations might also have contributed to the demonstration of symmetry.

As for Questions 1 to 3 about the baseline phase, all participants clearly reported the sample-comparison combinations for reinforcement. Therefore, they might have responded based on the verbal stimuli produced by their verbal behavior emitted to such sample-comparison combinations. In fact, when they were asked about rules of responding in the second and third questions, they reported that they responded based on their own rules about the sample-comparison combinations for reinforcement. Thus, the differentiation of responding they showed in the baseline phase might have been due to the verbal stimuli produced by their verbal behavior to the sample-comparison combinations for reinforcement. If so, their responding during the baseline phase might have been rule-governed behavior (cf. Skinner, 1966; 1969).

From the results of the interview in the baseline phase, the participants' responding in the test phase might also have reflected their naming produced by the verbal stimuli because non-reinforcement was in effect in all trials of each test session. Regarding Questions 4 to 8 concerning the test phase, all participants except PB2 referred to some new sample-comparison combinations. Moreover, they reported that the new sample-comparison combinations were the reverse of the combinations in reinforced symbolic matching baseline trials. Furthermore, all participants except PB2 reported that they responded in the new combination trials based on the same rules as those they described in the baseline phases. On the other hand, PB2 referred to the new combinations, but reported that she never responded in the new combination trials. Although PB2 did not report the reason for this, because of this non-responding strategy on the new combination trials, PB2 did not demonstrate symmetry. From all participants' replies, we should consider the possibility that participants' responding in the test phase might have been influenced by the verbal stimuli produced by their own verbal behavior. From their answers to the questions, the verbal behavior might have included naming to the sample and the comparison stimuli, linkage between the stimuli and description of the connection, and rehearsal of the names and the links. Furthermore, they described their rules specifying the contingencies of reinforcement on each reinforced trial during the baseline phase and used the rules on each positive trial in the test phase. Thus, the procedural change in this experiment facilitated not only differentiation of responding but also the participants' naming and rule-making. Therefore, symmetry demonstrated by the participants in the test phase 
might have been based not only on conditional discrimination in successive matching but also on their naming of each sample-comparison combination derived from the conditional stimulus control, as Fagot et al. (2017) reported.

\section{General Discussion}

From the results of the second experiment of this study, a successive matching procedure that facilitated differentiation of responding during the baseline training phase could have produced such symmetry for undergraduates as defined by Urcuioli (2008). The results of the first experiment can verify the conclusion because most participants in the first experiment who did not show clear differentiation of responding could not demonstrate symmetry; furthermore, when we changed the procedure to facilitate the differentiation of participants' responding, the number of participants who demonstrated symmetry increased. However, there was a possibility of naming that might have contributed to the formation of symmetry by participants in the second experiment. Even so, we do not believe that naming was the only fundamental process for symmetry because naming itself might have been facilitated by the procedural change from the first to the second experiment. We would rather say that naming may be a by-product of the contingencies of reinforcement as well as symmetry. As the results of the second experiment were explained by the procedural change from the first to the second experiment, we believe that not only symmetry but also naming was due to the change of contingencies of reinforcement in successive matching. This view is consistent with Urcuioli's claim (2015) that derived relations by non-verbal pigeons observed in his lab were products of their experimental procedure.

Our results could be explained by four assumptions of Urcuioli's theory (2008). The first assumption is that "the functional matching stimuli in pigeons' successive matching are compounds consisting of the nominal stimulus and when it appears in a matching trial". Although describing "pigeons" as the subjects in this assumption, this assumption is applicable to our findings of two experiments if the functional matching stimuli in this assumption can contain verbal stimuli produced by our participants' verbal behavior. From the participants' responses to the interview after the second experiment, we could infer various covert verbal behavior related to the sample-comparison combinations during the training and the test sessions in the second experiment. The verbal behavior might contain naming to the sample and the comparison stimuli, linkage between the stimuli and description of the connection, and rehearsal of the names and the links. If they emitted such covert verbal behavior during the training and the test sessions, each participant might have taken a role as a speaker-listener within the same skin (Horne \& Lowe, 1996). In this case, the verbal stimuli produced by the covert verbal behavior could be functional stimuli for the participant's responding. The possibility of such naming will be discussed again later. The temporal location of matching stimuli might also have been involved in the compounding because some participants referred to the temporal order of the stimuli as having the same physical properties.

The second assumption is that "the continuous juxtaposition of non-reinforced with reinforced sample-comparison combinations in successive matching facilitates stimulus class formation". Our participants' responding was also exposed to continuous juxtaposition of non-reinforced with reinforced sample-comparison combinations in the successive matching procedure. This is because we equalized the number of trials and the duration of comparison stimulus presentation between non-reinforced and reinforced sample-comparison combinations in the two experiments. Furthermore, in the second experiment, we equally held the duration of comparison stimulus presentation constant between reinforced and non-reinforced trials. By doing so, we could 
facilitate differentiation of responding and establishment of symmetry. Thus, the second assumption also explains our findings.

The third assumption is that "stimulus classes consist of the elements (the functional matching stimulus) of the reinforced trials". This assumption is also applicable to our findings if verbal stimuli produced by the participants' verbal behavior on reinforced trials were functional for their responses. Of course, the physical properties of the sample and the comparison stimuli on the reinforced trials might be the relevant elements of stimulus classes because our participants who demonstrated symmetry reported on the properties of the stimuli in the interviews after the experiments.

The final assumption is that "elements common to more than one stimulus class cause their respective classes to merge". As the training structure of the baseline phase was the same as Urcuioli's (2008), the stimuli of our three matching tasks (i.e., symbolic, hue-identity, and form-identity matching in the baseline phase) acted as elements common to more than one stimulus class. However, the merging behavioral processes might be different between pigeons and our participants because the verbal stimuli produced by the participants' verbal behavior might facilitate the process of making two or more stimulus classes combine into a single stimulus class. Even so, considering the verbal stimuli as a common element, we can say that the final assumption is applicable to our findings.

As described above, our findings can be explained by the four assumptions of Urcuioli's theory (2008). Thus, Urcuioli's theory can explain not only pigeons' stimulus class formation but also stimulus class formation by human participants. However, for humans, as stated earlier, we should consider the involvement of naming in the stimulus class formation in successive matching. As Urcuioli's theory does not address the involvement of naming in symmetry formation, we will first discuss the possibility of naming in our findings irrespective of Urcuioli's theory. Considering these again, we will then discuss the significance of Urcuioli's theory.

As already stated, our participants' answers to the questions after the second experiment contained various verbal behaviors, such as naming to the sample and comparison stimuli, the verbal behavior might have included naming to the sample and the comparison stimuli, linkage between the stimuli and description of the connection, and rehearsal of the names and the links. As the participants were undergraduates with sophisticated verbal repertoires, the possibility that their symmetry involves naming based on their verbal behavior was presumed.

Considering studies that have shown a close link between stimulus equivalence and language (e.g., D’Amato et al., 1985; Devaney et al., 1986; Eikeseth \& Smith, 1992; Lipkens et al., 1988; Lowe \& Beasty, 1987; Sidman, Kirk, \& Willson-Morris, 1985), Horne and Lowe (1996) expanded Skinner's (1957) conceptualization of human verbal behavior, emphasized the role of operant processes in language, and then offered a theoretical account of naming in equivalence. They defined naming as a basic unit of verbal behavior and as a higher order bidirectional relation between a class of objects or events and speaker-listener behavior (Horne \& Lowe, 1996). They hold that the bidirectional relation in naming is fundamental to the emergence of equivalence relations. A number of match-to-sample studies have indicated that stimulus equivalence in humans is the outcome of a number of different types of naming behavior and that naming enables emergent performances from which equivalence relations might be inferred (e.g., Dugdale \& Lowe, 1990; Eiketh \& Smith, 1992; Lowe \& Beasty, 1987; Randell \& Remington, 2006).

However, naming could be thought of as a mediator or a derivative of equivalence rather than a process fundamental to the emergence of equivalence relations (cf. Carr \& Blackman, 2001). The view of a mediator 
for emergent relations was traced back to Jenkins (1963), who described the emergence of a derived bidirectional relation in paired-associate verbal learning and referred to that as mediated transfer. After that, Sidman (1971) and Sidman and Cresson (1973) demonstrated mediated transfer by using a matching-to-sample procedure with retarded participants. Sidman, Cresson, and Wilson-Morris (1974) concluded that naming was not the mediator for the emergence of mediated transfer from their experimental results. Saunders (1989) challenged the possibility of naming as a mediator when he interpreted a demonstration of stimulus equivalence by monkeys (McIntire et al., 1987). Saunders (1989) claimed that "both stimulus equivalence and naming emerge as a result of the training procedures, and not that one (equivalence) depends upon the other (naming)" (p. 383, italics added). Considering these discussions about naming as a mediator, we believe that it is hard to regard the role of naming as a mediator to be fundamental to the emergence of symmetry.

The view of naming as a derivative of equivalence emphasizes the role of environmental contingencies that produce equivalence. The view regards naming as a byproduct of the contingencies. Saunders and Green (1992) claimed that "equivalence class formation may be a product of any procedure that serves to partition a set of stimuli into subsets of stimuli that are substitutable for one another in certain contexts" (p. 239). Furthermore, Saunders and Green (1996) insisted that "naming is neither necessary for, nor a more fundamental process than, the development of equivalence relations; rather, naming is made possible by contingencies that establish prerequisites for equivalence relations" (p. 314, italics added). Sidman (1994; 2000) has proposed that equivalence relations are a fundamental outcome of the environmental contingencies to which individuals are exposed. As for the naming controversy, Sidman (2000) claimed that

Any name we apply to stimuli is a defined discriminative response. ... any defined response components of the contingencies have a status that is equal in every way to the stimulus and reinforcer members of the classes. Although just as important, responses require no separate treatment. I think this provides a simple but satisfactory resolution to the naming controversy. (p. 145, italics added)

Carr and Blackman (2001) were also skeptical about the theoretical account of naming in equivalence by Horne and Lowe (1996). They referred to relational frame theory (Hayes, 1994; Hayes \& Hayes, 1992) that proposes that relational responding is derived as a behavioral principle from a history of responding in contextually controlled stimulus relations. From the interrelations among contextual control, equivalence relations, and naming, Carr and Blackman discussed the results of three experiments that investigated the effects of training class-inconsistent relations and naming on demonstrations of emergent arbitrary stimulus relations. They then concluded that their "results support the view that demonstrations of equivalence are subject to control from $a$ variety of sources rather than being fundamentally dependent on naming" (Carr \& Blackman, 2001, p. 55, italics added).

Thus, the above discussion about naming shows that even now no general agreement has been reached about the status of naming in equivalence, although the recent literature on stimulus equivalence has also drawn attention to a close connection between naming and equivalence (e.g., Jennings \& Miguel, 2017; Miguel, 2016).

Through the two present experiments, we have discussed that the verbal stimuli produced by our participants' verbal behavior might have contributed to the establishment of symmetry. These verbal stimuli might qualify as naming as defined by Horne and Lowe (1996). If so, naming might have been a source controlling our participants' responding in successive matching. How should we address the role of our 
participants' verbal behavior in the establishment of symmetry in successive matching? At least in our findings, even if our participants referred to the possibility of naming after the experiment, the role of naming in the foundation of symmetry remains open to debate, because we did not systematically investigate the possibility of naming in the course of the experiments. Additionally, we did not use difficult stimuli for naming and did not set up a control group that had no opportunities for naming. Furthermore, we did not conduct naming training to investigate the effects on the foundation of symmetry. Thus, it remains to be explained whether naming was indeed necessary for our participants' symmetry. However, even so, it seems unproductive to explain our findings only by naming. Our participants' behavior was certainly controlled by the contingencies of reinforcement in successive matching, because the procedural change from the first to the second experiment increased the number of participants who demonstrated such symmetry as defined by Urcuioli (2008).

Considering that our findings can be explained by the four assumptions of Urcuioli's theory (2008) rather than naming, we can offer a new interpretation about the behavioral processes necessary for symmetry in successive matching for his theory. Our findings may be better served by paying closer attention to how nonverbal and verbal behavioral processes interact in successive matching. If Urcuioli's theory is limited only to pigeons' behavior, even if his theory and experimental findings about pigeons' symmetry formation support Sidman's (2000) claim, we cannot help but state the limited significance of his theory. Such a limitation would lead us to attend only to biological differences between human and nonhuman animals. If he were to add an explanation of verbal behavioral processes to his model, we believe that his theory would be a more comprehensive account of equivalence in successive matching. Such foresight was implied in Urcuioli's (2015) own conclusion: "In sum, they demonstrate the powerful generative effects of reinforcement and stimulus control processes on behavior across many species" (p. 21, italics added). In view of this, we need further studies to investigate other emergent relations such as reflexivity, transitivity, anti-symmetry (but see Beurms et al., 2017), and anti-transitivity by human participants in successive matching.

From the above discussion and our findings, we believe that emergent relations, such as symmetry in successive matching, are products of various verbal and nonverbal behavioral processes and that this view would be consistent with Sidman's (2000) claim that "equivalence is a direct outcome of reinforcement contingencies" (pp. 127-128).

\section{Conflicts of Interest}

The authors declare that there are no conflicts of interest.

\section{References}

Beurms, S., Traets, F., De Houwer, J., \& Beckers, T. (2017). Symmetry and stimulus class formation in humans: Control by temporal location in a successive matching task. Journal of the Experimental Analysis of Behavior, 108, 335-350. doi:10.1002/jeab.282

Carr, D., \& Blackman, D. E. (2001). Relations among equivalence, naming, and conflicting baseline control. Journal of the Experimental Analysis of Behavior, 75, 55-76. doi:10.1901/jeab.2001.75-55

Catania, A. C. (2013). Learning (5th ed.). Hudson, NY: Sloan Publishing.

D’Amato, M. R., Salmon, D. P., Loukas, E., \& Tomie, A. (1985). Symmetry and transitivity of conditional relations in monkeys (Cebusapella) and pigeons (Columba livia). Journal of the Experimental Analysis of Behavior, 44, 35-47. doi:10.1901/jeab.1985.44-35

Devaney, J. M., Hayes, S. C., \& Nelson, R. O. (1986). Equivalence class formation in language-able and language-disabled children. Journal of Applied Behavior Analysis, 46, 243-257. doi:10.1901/jeab.1986.46-243 
Dugdale, N., \& Lowe, C. F. (2000). Testing for symmetry in the conditional discriminations of language-trained chimpanzees. Journal of the Experimental Analysis of Behavior, 73, 5-22. doi:10.1901/jeab.2000.73-5

Dugdale, N. A., \& Lowe, C. F. (1990). Naming and stimulus equivalence. In D. E. Blackman and H. Lejeune (Eds.), Behaviour analysis in theory and practice: Contributions and controversies (pp. 115-138). Hove, England: Erlbaum.

Eikeseth, S., \& Smith, T. (1992). The development of functional and equivalence classes in high-functioning autistic children: The role of naming. Journal of the Experimental Analysis of Behavior, 58, 123-133. doi:10.1901/jeab.1992.58-123

Fagot, J., Malassis, R., \& Medam, T. (2017). The processing of positional information in a two-item sequence limits the emergence of symmetry in baboons (Papio papio), but not in humans (Homo sapiens). Learning \& Behavior, 46, 67-78. doi:10.3758/s13420-017-0290-1

Frank, A. J., \& Wasserman, E. A. (2005). Associative symmetry in the pigeon after successive matching-to-sample training. Journal of the Experimental Analysis of Behavior, 84, 147-165. doi:10.1901/jeab.2005.115-04

Gómez, J., García, A., \& Pérez, V. (2014). Failure to find symmetry after multiple exemplar training. Psicothema, 26, 434-441.

Hayes, S. C. (1989). Nonhumans have not yet shown stimulus equivalence. Journal of the Experimental Analysis of Behavior, 51, 385-392. doi:10.1901/jeab.1989.51-385

Hayes, S. C. (1994). Relational frame theory: A functional approach to verbal events. In S. C. Hayes, L. J. Hayes, M. Sato, and K. Ono (Eds.), Behavior analysis of language and cognition (pp. 9-30). Reno, NV: Context Press.

Hayes, S. C., \& Hayes, L. J. (1992). Verbal relations and the evolution of behavior analysis. American Psychologist, 47, 1383-1395. doi:10.1037/0003-066X.47.11.1383

Hinde, R. A., \& Stevenson-Hinde, J. (1973). Constraints on learning: Limitations and predispositions. New York: Academic Press.

Hogan, D. E., \& Zentall, T. R. (1977). Backward associations in the pigeon. Journal of the Experimental Analysis of Behavior, 90 , 3-15.

Holmes, P. W. (1979). Transfer of matching performance in pigeons. Journal of the Experimental Analysis of Behavior, 31, 103-114. doi:10.1901/jeab.1979.31-103

Horne, P. J., \& Lowe, C. F. (1996). On the origins of naming and other symbolic behavior. Journal of the Experimental Analysis of Behavior, 65, 185-241. doi:10.1901/jeab.1996.65-185

Horne, P. J., \& Lowe, C. F. (1997). Toward a theory of verbal behavior. Journal of the Experimental Analysis of Behavior, 68, 271-296. doi:10.1901/jeab.1997.68-271

Jenkins, J. J. (1963). Mediated associations: Paradigms and situations. In C. N. Cofer and B. S. Musgrave (Eds.), Verbal behavior and learning: Problems and processes (pp. 210-245). New York: McGraw-Hill.

Jennings, A. M., \& Miguel, C. F. (2017). Training intraverbal bidirectional naming to establish generalized equivalence class performances. Journal of the Experimental Analysis of Behavior, 108, 269-289. doi:10.1002/jeab.277

Lionello, K. M., \& Urcuioli, P. J. (1998). Control by sample location in pigeons' matching to sample. Journal of the Experimental Analysis of Behavior, 70, 235-251. doi:10.1901/jeab.1998.70-235

Lionello-DeNolf, K. M. (2009). The search for symmetry: 25 years in review. Learning \& Behavior, 37, $188-203$. doi:10.3758/LB.37.2.188

Lionello-DeNolf, K. M., \& Urcuioli, P. J. (2000). Transfer of pigeons' matching-to-sample to novel sample locations. Journal of the Experimental Analysis of Behavior, 73, 141-161. doi:10.1901/jeab.2000.73-141

Lionello-DeNolf, K. M., \& Urcuioli, P. J. (2002). Stimulus control topographies and tests of symmetry in pigeons. Journal of the Experimental Analysis of Behavior, 78, 467-495. doi:10.1901/jeab.2002.78-467

Lipkens, R., Kop, P. F. M., \& Matthijs, W. A. (1988). A test of symmetry and transitivity in the conditional discrimination performances of pigeons. Journal of the Experimental Analysis of Behavior, 49, 395-409. doi:10.1901/jeab.1988.49-395

Lowe, C. F., \& Beasty, A. (1987). Language and the emergence of equivalence relations: A developmental study. Bulletin of the British Psychological Society, 40, A49.

McIntire, K. D., Cleary, J., \& Thompson, T. (1987). Conditional relations by monkeys: Reflexivity, symmetry, and transitivity. Journal of the Experimental Analysis of Behavior, 47, 279-285. doi:10.1901/jeab.1987.47-279

Meehan, E. F. (1999). Class-consistent differential reinforcement and stimulus class formation in pigeons. Journal of the Experimental Analysis of Behavior, 72, 97-115. doi:10.1901/jeab.1999.72-97

Miguel, C. F. (2016). Common and intraverbal bidirectional naming. The Analysis of Verbal Behavior, 32, $125-138$. doi:10.1007/s40616-016-0066-2 
Randell, T., \& Remington, B. (2006). Equivalence relations, contextual control, and naming. Journal of the Experimental Analysis of Behavior, 86, 337-354. doi:10.1901/jeab.2006.82-05

Richards, R. W. (1988). The question of bidirectional associations in pigeons' learning of conditional discrimination tasks. Bulletin of the Psychonomic Society, 26, 577-579. doi:10.3758/BF03330126

Rodewald, H. K. (1974). Symbolic matching-to-sample by pigeons. Psychological Reports, 34, 987-990. doi:10.2466/pr0.1974.34.3.987

Saunders, K. J. (1989). Naming in conditional discrimination and stimulus equivalence. Journal of the Experimental Analysis of Behavior, 51, 379-384. doi:10.1901/jeab.1989.51-379

Saunders, R. R., \& Green, G. (1992). The nonequivalence of behavioral and mathematical equivalence. Journal of the Experimental Analysis of Behavior, 57, 227-241. doi:10.1901/jeab.1992.57-227

Saunders, R. R., \& Green, G. (1996). Naming is not (necessary for) stimulus equivalence. Journal of the Experimental Analysis of Behavior, 65, 312-314. doi:10.1901/jeab.1996.65-312

Schusterman, R. J., \& Kastak, D. (1993). A California sea lion (Zalophus californianus) is capable of forming equivalence relations. The Psychological Record, 43, 823-839. doi:10.1007/BF03395915

Sidman, M. (1971). Reading and auditory-visual equivalence. Journal of Speech and Research, 14, 5-13.

Sidman, M. (1987). Two choices are not enough. Behavior Analysis, 22, 11-18.

Sidman, M. (1990). Equivalence relations: Where do they come from? In D. E. Blackman and H. Lejeune (Eds.), Behaviour analysis in theory and practice: Contributions and controversies (pp. 93-114). Hillsdale, NJ: Erlbaum.

Sidman, M. (1994). Equivalence relations and behavior: A research story. Boston: Authors Cooperative.

Sidman, M. (2000). Equivalence relations and the reinforcement contingency. Journal of the Experimental Analysis of Behavior, 74, 127-146. doi:10.1901/jeab.2000.74-127

Sidman, M. (2008). Symmetry and equivalence relations in behavior. Cognitive Studies, 15, 322-332. doi:10.11225/jcss.15.322

Sidman, M., \& Cresson Jr., O. (1973). Reading and cross modal transfer of stimulus equivalence in severe retardation. American Journal of Mental Deficiency, 77, 515-523.

Sidman, M., Cresson Jr., O., \& Willson-Morris, M. (1974). Acquisition of matching to sample via mediated transfer. Journal of the Experimental Analysis of Behavior, 22, 261-273.

Sidman, M., Kirk, B., \& Willson-Morris, M. (1985). Six-member stimulus classes generated by conditional-discrimination procedures. Journal of the Experimental Analysis of Behavior, 43, 21-42. doi:10.1901/jeab.1985.43-21

Sidman, M., Rauzin, R., Lazar, R., Cunningham, S., Tailby, W., \& Carrigan, P. (1982). A search for symmetry in the conditional discriminations of rhesus monkeys, baboons, and children. Journal of the Experimental Analysis of Behavior, 37, 23-44. doi:10.1901/jeab.1982.37-23

Sidman, M., \& Tailby, W. (1982). Conditional discrimination vs. matching to sample: An expansion of the testing paradigm. Journal of the Experimental Analysis of Behavior, 37, 5-22. doi:10.1901/jeab.1982.37-5

Skinner, B. F. (1957). Verbal behavior. New York: Appleton-Century-Crofts.

Skinner, B. F. (1966). An operant analysis of problem solving. In B. Kleinmuntz (Ed.), Problem solving: Research, method, and theory (pp. 225-257). New York: John Wiley.

Skinner, B. F. (1969). Contingencies of reinforcement: A theoretical analysis. New York: Appleton-Century-Crofts.

Sweeney, M. M., \& Urcuioli, P. J. (2010). Reflexivity in pigeons. Journal of the Experimental Analysis of Behavior, 94, $267-282$. doi:10.1901/jeab.2010.94-267

Swisher, M., \& Urcuioli, P. J. (2015). Symmetry in the pigeon with sample and comparison stimuli in different locations. II. Journal of the Experimental Analysis of Behavior, 104, 119-132. doi:10.1002/jeab.162

Swisher, M., \& Urcuioli, P. J. (2018). Reflexivity without identity matching training: a first demonstration. Journal of the Experimental Analysis of Behavior, 109, 125-147. doi:10.1002/jeab.302

Tomonaga, M., Matsuzawa, T., Fujita, K., \& Yamamoto, J. (1991). Emergence of symmetry in a visual conditional discrimination by chimpanzees (Pan troglodytes). Psychological Reports, 68, 51-60. doi:10.2466/pr0.1991.68.1.51

Urcuioli, P. J. (2008). Associative symmetry, antisymmetry, and a theory of pigeons' equivalence-class formation. Journal of the Experimental Analysis of Behavior, 90, 257-282. doi:10.1901/jeab.2008.90-257

Urcuioli, P. J. (2015). A successful search for symmetry (and other derived relations) in the conditional discriminations of pigeons. Conductual, International Journal of Interbehaviorism and Behavior Analysis, 3, 4-25.

Urcuioli, P. J., \& Swisher, M. J. (2012). A replication and extension of the antisymmetry effect in pigeons. Journal of the Experimental Analysis of Behavior, 98, 283-293. doi:10.1901/jeab.2012.98-283 
Urcuioli, P. J., \& Swisher, M. J. (2015). Transitive and anti-transitive emergent relations in pigeons: Support for a theory of stimulus-class formation. Behavioural Processes, 112, 49-60. doi:10.1016/j.beproc.2014.07.006

Velasco, S. M., Huziwara, E. M., Machado, A., \& Tomanari, G. Y. (2010). Associative symmetry by pigeons after few-exemplar training. Journal of the Experimental Analysis of Behavior, 94, 283-295. doi:10.1901/jeab.2010.94-283

Yamamoto, J., \& Asano, T. (1995). Stimulus equivalence in a chimpanzee (Pan troglodytes). The Psychological Record, 45, 3-21. 